\title{
Comparison of the Velocity and Power Parameters During Loaded-Squat Jump Exercise of National Athletes in Different Branches*
}

\author{
Ibrahim Can ${ }^{1}$, Hamit Cihan ${ }^{2}$, Erdal Ari ${ }^{3}$, Serdar Bayrakdaroglu ${ }^{1}$ \\ ${ }^{1}$ Gümüşhane Üniversity, School of Physical Education and Sport, Gümüşhane, Turkey \\ ${ }^{2}$ Karadeniz Teknik University, School of Physical Education and Sport, Trabzon, Turkey \\ ${ }^{3}$ Ordu University, School of Physical Education and Sport, Ordu, Turkey \\ Correspondence: Ibrahim Can, Gümüşhane Üniversity, School of Physical Education and Sport, Gümüşhane, Turkey.
}

Received: February 25, 2018

Accepted: March 21, 2018

Online Published: March 25, 2018

doi:10.11114/jets.v6i5.3132

URL: https://doi.org/10.11114/jets.v6i5.3132

\begin{abstract}
The aim of this investigation is to compare velocity and power variables during loaded-squat jump $\left(\mathrm{SJ}_{\text {Loaded }}\right)$ exercise of national athletes dealing with different sports branches and to identify whether velocity and power parameters become different or not according to branches. In accordance with this purpose, a total of 36 national athletes (age: $20.3 \pm 1.68$ years; height: $173.5 \pm 6.46 \mathrm{~cm}$; weight: $72.3 \pm 10.29 \mathrm{~kg}$ ) composed of 12 wrestlers (age: $19.5 \pm .90$ years; height: $172.3 \pm 6.19 \mathrm{~cm}$; weight: $75.5 \pm 13.9 \mathrm{~kg}$ ), 12 arm wrestlers (age: $20.5 \pm 2.02$ years; height: $174.7 \pm 4.76 \mathrm{~cm}$; weight: $72.6 \pm 8.31 \mathrm{~kg}$ ) and 12 kickboxers (age: $20.7 \pm 1.81$ years; height: $173.5 \pm 8.29 \mathrm{~cm}$; weight: $68.9 \pm 6.94 \mathrm{~kg}$ ) dealing with different sports branches have voluntarily participated in this study. For identifying velocity and power parameters, $\mathrm{SJ}_{\text {Loaded }}$ exercise was executed with an external load that corresponds to $40 \%$ of body weights of the athletes by utilizing an isoinertial velocity transducer (T-Force dynamic measurement system) and values of mean velocity (MV), mean propulsive velocity (MPV), peak velocity (PV), mean power (MP), mean propulsive power (MPP) and peak power (PP) were determined. All data analyzes were performed in the SPSS 16.0 statistical program. Firstly, in order to analyze data, it was determined that the data indicated normal distribution by looking at the Shapiro-Wilk coefficient regarding the normality of the distribution of the data. Therefore one-way analysis of variance (One-way ANOVA) was utilized to identify statistical significant differences among athletes competing in different branches with regard to the velocity and power variables during the $\mathrm{SJ}_{\text {Loaded }}$ exercise. According to analyze results, no statistical significant difference wasn't seen among branches with regard to MV [f $(2.33)=1.306$ ], MPV [f (2. 33)=2.195], PV [f (2. 33)=2.242], MP [f ( 2. $33)=1.225]$, MPP [ $(2.33)=2.787]$ and $\mathrm{PP}[\mathrm{f}(2.33)=2.607]$ parameters during $\mathrm{SJ}_{\text {Loaded }}$ exercise $(\mathrm{p}>0.05)$. The velocity and power parameters obtained in the $\mathrm{SJ}_{\text {Loaded }}$ exercise don't differ according to the branches.
\end{abstract}

Keywords: squat jump, velocity, power

\section{Introduction}

It is believed that kinetics and kinematics related to resistance trainings are an important stimulant in consist of neuromuscular adaptations (Crewther et al, 2006). A stimulated muscle performes a strength against the tendons that provide the transfer to the skeletal structure by attempting to contract and the natural resistors exposed during the muscular movement determine the resulting movement (Aşç1, 2001). In other words, the muscle has the ability to adjust a counter-force that can withstand the resistance applied to itself during shortening and this attribute depends on continuous adjustment of the speed created by the muscular contraction system against an external resistance (Edman $e t$ al., 1978). The power and strength characteristics (Harman, 2008) used to describe some crucial abilities that participate to peak human effort in sports activities or other physical exercises are crucial at sport events requiring an ability of creating a considerably high force against high work rate (power) and great resistances (strength). For this reason, the achievement in several sports branches depends on the player's maximal strength and explosive leg power to a large extent (Yessin \& Hatfield, 2007).

\footnotetext{
"This study is presented as oral presentation in the "'World Congress of Sport Sciences Researches" which was hosted by the Manisa Celal Bayar University, 23 to $26^{\text {th }}$ October 2017.
} 
Power being one of the crucial component of sportive performance (Newton \& Kraemer, 1994; Young etal, 2005; Cronin \& Sleivert, 2005) is the mechanic amount stated as the temporal rate of the work done (Enoka, 1994) and it usually relates to the ability of being able to reveal the possible maximal strength (Stone et al., 2003). Thus, if maximal strength values of athletes is similar, the individual releasing the strength values with higher speeds (or in a short time) will get a more pronounced advantage with regard to performance in anaerobic sport branches (Ratamess, 2012). An increase in power gives the athlete an advanced athletic performance in which an improved quick-power relationship is sought (Sankarmani et al., 2012). Power can be expressed as one movement, movement series or multiple motion repetitions in aerobic exercise. It can also be determined as average or immediately for the exercise period or any state of movement (Knuttgen \& Komi, 2003).

Velocity expressed as vector amaunt, is the temporal rate of alteration in positions (Zatsiorsky, 1998). Strength-velocity of muscular contraction relation - first expressed in 1930s - indicates an opposite relation between strength of muscular contraction and velocity of contraction. In other words, as the weight increases, the strength produced by the muscle rises and the motion velocity diminishes (Boreham, 2006). This circumstance is true experimentally. If the weight is heavy in bench press movement, athlete will perform exercise with low velocities. But if it is desired to make the movement in half of the maximal, athlete will perform exercise with higher velocities (Kraemer \& Vinger, 2007). The velocity of movement is an crucial factor to follow intensity of exercise (Sanchez-Medina et al., 2010) and the movement velocity in exercise is able to be an important reference for the real effort exerted by the athlete. In an investigation of Gonzales-Badillo and Sanchez-Medina (2010), it has been concluded that every $5 \%$ rise in relative load (among 30-100\% of one-repetition maximum) results in difference of 0.07-0.09 m.s- ${ }^{1}$ in velocity of movement.

As far as we have examined the literature, no research has been performed before to compare the velocity and power parameters of the national athletes in different branches on loaded-squat jump movement. Determining velocity and power parameters is able to be beneficial while ascertaining specific characteristics of training in sport branches requiring explosiveness in different movements. The aim of this investigation is to compare velocity and power parameters in $\mathrm{SJ}_{\text {Loaded }}$ movement of national athletes dealing with different branches and to identify whether velocity and power parameters become different or not according to the branches.

\section{Material and Method}

\subsection{Participants}

A total of 36 national athletes (age: $20.3 \pm 1.68$ years; height: $173.5 \pm 6.46 \mathrm{~cm}$; weight: $72.3 \pm 10.29 \mathrm{~kg}$ ) composed of 12 wrestlers (age: $19.5 \pm .90$ years; height: $172.3 \pm 6.19 \mathrm{~cm}$; weight: $75.5 \pm 13.9 \mathrm{~kg}$ ), 12 arm wrestlers ( age: $20.5 \pm$ 2.02 years; height: $174.7 \pm 4.76 \mathrm{~cm}$; weight: $72.6 \pm 8.31 \mathrm{~kg}$ ) and 12 kickboxers (age: $20.7 \pm 1.81$ years; height: $173.5 \pm$ $8.29 \mathrm{~cm}$; weight: $68.9 \pm 6.94 \mathrm{~kg}$ ) dealing with different sports branches have voluntarily participated in this study.

\subsection{Procedures}

Height and body weight measurements of the athletes were determined by using a Seca769 electronic measuring instrument (SecaCorporation, Hamburg, Germany) with an accuracy of $0.001 \mathrm{~m}$ and $0.01 \mathrm{~kg}$, sequentially. After the physical characteristics of the participants were determined, the external load being equivalent to $40 \%$ of body weight was determined. Before the loaded-squat jump ( $\left.\mathrm{SJ}_{\text {Loaded }}\right)$ exercise was applied, a total of 20 minutes of standard warm-up - composed of 15 minutes of general ( 5 minutes stretching for lower body stretching after 10 minutes of running) and 5 minutes of specific exercises (squat exercise performing with submaximal intensity)- was applied to the participants. After the warm-up, loaded-squat jump movement was executed with an load that corresponds to $40 \%$ of body weights of the subjects by using free weight. During test, athletes must bring their knees to the flexion situation until their thighs were straight to floor from stationary situation, to jump quickly without losing touch between their shoulders and bar following the start command and to repeat it 3 times (Loturco et al., 2015). These movements were repeated when these requirements were not fulfilled. Since, body weight must be moved as well as the external load in the $\mathrm{SJ}_{\text {Loaded }}$ movement and variables as velocity and power must be identified thanks to the ability to accelerate the total mass (body weight and additional load) of the subject (Cormie et al., 2007). A linear transducer device (T-Force Dynamic Measurement System; Ergotech Consulting S.L, Murcia, Spain) was attached to the last section of the bar to identify velocity and power values. Utilizing of linear transducer system is proper particularly for weight lifting movement or exercises performed in resistance training including to accomplish a load (permanent mass) moving throughout a vertical axis versus gravitation. The measuring system comprise of an electromechanics hardware consisting of velocity sensor and interface, a software (software of T-Force system) and a grapple attached to weight lifted by athletes (Sanchez-Medina et al., 2010, 2014).

\subsection{Statistical Analysis}

For the analysis of data, it has been determined that the distribution of data is normal by looking at the Shapiro-Wilk 
coefficient related to the normality of the distribution of data. One-way variance analysis (One-way ANOVA) was performed for determining differences between velocity and power parameters in $\mathrm{SJ}_{\text {Loaded }}$ exercise of athletes in different branches. All variables were expressed as mean and standard deviation. SPSS software 16.0 (SPSS Inc, Chicago, IL) was utilized for all statistical Analyzes. The statistical analyzes was performed in $\mathrm{p}<0.05$ significiance level.

\section{Results}

The physical characteristics of the athletes were presented in table 1 and the results of descriptive statistical pertaining to velocity and power parameters in $\mathrm{SJ}_{\mathrm{Loaded}}$ exercise were presented in table 2 . The comparison results of velocity and power parameters in $\mathrm{SJ}_{\text {Loaded }}$ exercise according to sport branches were presented in table 3 .

Table 1. Physical Characteristics of the Athletes

\begin{tabular}{lllllllll}
\hline \multicolumn{1}{c}{} & \multicolumn{9}{c}{ Variables } \\
\hline Branches & $\mathbf{n}$ & \multicolumn{1}{c}{ Age (year) } & \multicolumn{3}{c}{ Height $(\mathbf{c m})$} & Weight (kg) \\
\hline & & Min. & Max. & Mean $(\mathrm{sd})$ & Min. & Max. & Mean $(\mathrm{sd})$ & Min. Max.Mean $(\mathrm{sd})$ \\
Wrestling & 12 & 18.00 & 21.00 & $19.5( \pm .90)$ & 158.0 & 183.0 & $172.3( \pm 6.19)$ & $52.998 .975 .5( \pm 13.9)$ \\
Arm wrestling & 12 & 18.00 & 24.00 & $20.5( \pm 2.02)$ & 168.0 & 184.0 & $174.7( \pm 4.76)$ & $55.284 .172 .6( \pm 8.31)$ \\
Kickbox & 12 & 18.00 & 24.00 & $20.7( \pm 1.81)$ & 164.0 & 185.0 & $173.5( \pm 8.29)$ & $58.779 .568 .9( \pm 6.94)$ \\
Total & 36 & 18.00 & 24.00 & $20.3( \pm 1.68)$ & 158.0 & 185.0 & $173.5( \pm 6.46)$ & $52.998 .972 .3( \pm 10.29)$ \\
\hline
\end{tabular}

Table 2. Descriptive Statistical Results Pertaining to Velocity and Power Parameters in Loaded-Squat Jump Exercise

\begin{tabular}{lllllllllll}
\hline \multicolumn{1}{c}{ Variables } \\
\hline \multicolumn{1}{c}{ Wrestling } & \multicolumn{3}{c}{ Arm Wrestling } \\
\hline Variables & n & Min. & Max. & Mean (sd) & Min. & Max. & Mean (sd) & Min. & Max. & Mean (sd) \\
\hline MV $\left(\mathrm{m} / \mathrm{s}^{-1}\right)$ & 12 & 1.09 & 1.51 & $1.23( \pm .12)$ & .91 & 1.34 & $1.15( \pm .10)$ & .94 & 1.44 & $1.20( \pm .14)$ \\
MPV $\left(\mathrm{m} / \mathrm{s}^{-1}\right)$ & 12 & 1.19 & 1.68 & $1.35( \pm .14)$ & .95 & 1.47 & $1.22( \pm .12)$ & 1.01 & 1.62 & $1.31( \pm 1.81)$ \\
PV $\left(\mathrm{m} / \mathrm{s}^{-1}\right)$ & 12 & 1.92 & 2.83 & $2.31( \pm .25)$ & 1.79 & 2.40 & $2.12( \pm .17)$ & 1.88 & 2.61 & $2.25( \pm .24)$ \\
MP $(\mathrm{W})$ & 12 & 248.1 & 446.0 & $359.8( \pm 67.5)$ & 194.1 & 437.6 & $327.0( \pm 63.7)$ & 222.5 & 423.4 & $324.7( \pm 51.6)$ \\
MPP $(\mathrm{W})$ & 12 & 348.4 & 874.6 & $558.6( \pm 139.7)$ & 257.1 & 650.7 & $443.7( \pm 112.2)$ & 323.4 & 677.1 & $483.1( \pm 108.7)$ \\
PP $(\mathrm{W})$ & 12 & 574.1 & 1517.3 & $1007.8( \pm 239.1)$ & 498.6 & 1074.9 & $834.8( \pm 157.0)$ & 624.4 & 1193.3 & $892.6( \pm 158.5)$ \\
\hline
\end{tabular}

MV: Mean Velocity; MPV: Mean Propulsive Velocity; PV: Peak Velocity; MP: Mean Power; MPP: Mean Propulsive Power; PP: Peak Power

Table 3. One-Way Variance Analysis Comparing Velocity and Power Parameters in Loaded-Squat Jump Exercise According to Branches

\begin{tabular}{|c|c|c|c|c|c|c|}
\hline & & Sum of Squares & df & Mean Square & $\mathbf{F}$ & Significance \\
\hline \multirow[t]{3}{*}{ MV } & Between Groups & .042 & 2 & .021 & & \\
\hline & Within Groups & .533 & 33 & .016 & 1.306 & .285 \\
\hline & Total & .575 & 35 & & & \\
\hline \multirow[t]{3}{*}{ MPV } & Between Groups & .104 & 2 & .052 & & \\
\hline & Within Groups & .778 & 33 & .024 & 2.195 & .127 \\
\hline & Total & .882 & 35 & & & \\
\hline \multirow[t]{3}{*}{ PV } & Between Groups & .236 & 2 & .118 & & \\
\hline & Within Groups & 1.736 & 33 & .053 & 2.242 & .122 \\
\hline & Total & 1.972 & 35 & & & \\
\hline \multirow[t]{3}{*}{ MP } & Between Groups & 9221.571 & 2 & 4610.785 & & \\
\hline & Within Groups & 124197.539 & 33 & 3763.562 & 1.225 & .307 \\
\hline & Total & 133419.110 & 35 & & & \\
\hline \multirow[t]{3}{*}{ MPP } & Between Groups & 81671.042 & 2 & 40835.521 & & \\
\hline & Within Groups & 483486.550 & 33 & 14651.108 & 2.787 & .076 \\
\hline & Total & 565157.592 & 35 & & & \\
\hline \multirow[t]{3}{*}{ PP } & Between Groups & 185990.645 & 2 & 92995.323 & & \\
\hline & Within Groups & 1176953.645 & 33 & 35665.262 & 2.607 & .089 \\
\hline & Total & 1362944.290 & 35 & & & \\
\hline
\end{tabular}

p>0.05; MV: Mean Velocity; MPV: Mean Propulsive Velocity; PV: Peak Velocity; MP: Mean Power; MPP: Mean Propulsive Power; PP: Peak Power

Regarding table 3, it is observed that there isn't statistical significant difference among the branches in relation to MV, MPV, PV, MP, MPP and PP parameters in $\mathrm{SJ}_{\text {Loaded }}$ exercise.

\section{Discussion and Conclusion}

In this study comparing power (MP, MPP, PP) and velocity (MV, MPV, PV) parameters during $\mathrm{SJ}_{\text {Loaded }}$ movement of 
national athletes who are engaged in different sports branches and analyzing whether these parameters become different as per the branches, it has been observed that there isn't significant discrepancy statistically among the branches in respect to both velocity and power parameters. In literature, no study has been performed before to compare the velocity and power parameters of the national athletes in different branches during $\mathrm{SJ}_{\text {Loaded }}$ exercise. Only in the study of Can (2017) conducted on handball players competing in the Handball $1^{\text {st }}$ League and arm wrestlers being placed in European and World arm wrestling championships, velocity and power parameters of both groups during $\mathrm{SJ}_{\text {Loaded }}$ exercise were compared. In the mentioned study, it has been determined that branches differentiated with regards to MV and PV values during the $\mathrm{SJ}_{\text {Loaded }}$ exercise and arm wrestlers have a better velocity values during weight lifting than the handball players. Due to the fact that jumping feature in handball is an important performance indicator and jump exercises are included in training programs, it is a surprising result that the arm wrestlers have a better value than the handball players in terms of velocity parameters while handball players are expected to have better jump speed. It has been argued that physical characteristics and level of struggle are important factors in the emergence of such a result. For instance, due to the fact that handball players compete in the $1^{\text {st }}$ league while arm wrestlers are composed of the athletes being placed in European and World arm wrestling championships and handball players weigh more, it has been suggested that their jumps with heavier loads may cause their lifting velocity to be low. Moreover, it has been obtained that there isn't significant discrepancy statistically among the branches in respect to power parameters.

In some studies, kinetic or/and kinematic values of athletes struggling in different branches obtained in jump exercises were compared. In a research conducted by Dal Pupo et al., (2012), they have found that sprinter has better value than volleyball players in terms of peak velocity parameter in both squat jump and countermovement jump exercise and suggested that the difference may be due to the training protocol applied by the sprinters. Kollias et al., (2001) has reported that velocity values of sprint runners during vertical-jump movement are higher than basketball, football and volleyball players. In the study of Loturco et al., (2014), jump velocities of Brazilian national karate players during $\mathrm{SJ}_{\text {Loaded }}$ movement performed with an outer load equaled to $40 \%$ of athlete's weights were found as $1.23\left( \pm, 15 \mathrm{~m} \cdot \mathrm{s}^{-1}\right)$. Can (2017) has found the mean velocity of national arm wrestlers and the handball players of the $1^{\text {st }}$ league during $\mathrm{SJ}_{\text {Loaded }}$ movement applied with an outer load equaled to $40 \%$ of subject's weights as $1.21\left( \pm, 09 \mathrm{~m} . \mathrm{s}^{-1}\right)$ and $1.10( \pm, 07$ $\left.\mathrm{m} . \mathrm{s}^{-1}\right)$ respectively. In this study, mean velocity values were found as $1.23\left( \pm, 12 \mathrm{~m} . \mathrm{s}^{-1}\right)$ for national athletes, $1.15( \pm 10$ $\left.\mathrm{m} \cdot \mathrm{s}^{-1}\right)$ for arm wrestlers and $1.20\left( \pm, 14 \mathrm{~m} \cdot \mathrm{s}^{-1}\right)$ for kickboxing athletes. As can be observed from these results, it can be argued that the increase in the level of fighting in the athletes also increases the velocity of the lifts.

In conclusion, this research is the first one in that it compares velocity and power parameters of national athletes competing in different branches during $\mathrm{SJ}_{\text {Loaded }}$ exercise. Therefore, it is thought that these findings reached can be an important reference source for future investigations. Velocity and power parameters can be different according to movements applied in the every sports branch. Obtaining power and velocity values can be beneficial while ascertaining specific training characteristics in branches requiring explosiveness in different movements.

\section{References}

Aşçı, A. (2001). The Determination of Strength Threshold in Explosive Strength Development (Unpublished Doctoral Thesis), Hacettepe University, Ankara.

Boreham, C. (2006). The Physiology of Sprint and Power Training. Whyte, G. (Ed.). The Physiology of Training: Advances in Sport and Exercise Science Series. Philadelphia: Churchill Livingstone Elsevier. https://doi.org/10.1016/B978-0-443-10117-5.50011-8

Can, I. (2017). Comparison of Power, Velocity and Force Parameters during Loaded Squat Jump Exercise in the Handball and Arm Wrestling Players. Journal of Education and Training Science, 5(12), 92-98. https://doi.org/10.11114/jets.v5i12.2057

Cormie, P., McCaulley, G. O., Triplett, N. T., \& McBride, J. M. (2007). Optimal Loadig for Maximal Power Output During Lower Body Resistance Exercises, Medicine and Science in Sports and Exercise, 39(2), 340-349. https://doi.org/10.1249/01.mss.0000246993.71599.bf

Crewther, B., Cronin, J., \& Koegh, J. (2006). Possible Stimuli for Strength and Power Adaptation: Acute Mechanical Responses. Sports Medicine, 36(1), 65-78. https://doi.org/10.2165/00007256-200636010-00005

Cronin, J. B., \& Sleivert, G. (2005). Challenges in Understanding the Influence of Maximal Power Training on Improving Athletic Performance. Sports Medicine, 35(3), 213-234. https://doi.org/10.2165/00007256-200535030-00003

Dal-Pupo, J., Detanico, D., \& Dos-Santos, S. G. (2012). Kinetic Parameters As Determinants of Vertical Jump Performance. Brazilian Journal of Kinanthropometry and Human Performance, 14(1), 41-51.

Edman, K. A. P., Elzinga, G., \& Noble, M. I. M. (1978). Enhancement of Mechanical Performance by Stretch During 
Tetanic Contractions of Vertebrate Skeletal Muscle Fibers. The Journal of Physiology, 281, 139-155. https://doi.org/10.1113/jphysiol.1978.sp012413

Enoka, R. M. (1994). Neuromechanical Basis of Kinesiology. (2 ${ }^{\text {nd }}$ Edition). Champaign, IL: Human Kinetics.

Gonzales-Badillo, J. J., \& Sanchez-Medina, L. (2010). Movement Velocity As a Measure of Loading Intensity in Resistance Training. International Journal of Sports Medicine, 31(5), 347-352. https://doi.org/10.1055/s-0030-1248333

Harman, E. (2008). Biomechanics of Resistance Exercise. Beachle, T.R., and Earle, W.R. (Ed.). Essentials of Strength Training and Conditioning, ( $3^{\text {rd }}$ Edition). Champaign, IL: Human Kinetics.

Knuttgen, H. G., \& Komi, P. V. (2003). Basic Considerations for Exercise. Komi, P.V. (Ed.), Strength and Power in Sport, ( $2^{\text {nd }}$ Edition). Oxford: Blackwell Science Ltd. https://doi.org/10.1002/9780470757215.ch1

Kollias, I., Hatzitaki, V., Papaiakovou, G., \& Giatsis, G. (2001). Using Principal Componenets Analysis to Identify Individual Differences in Vertical Jump Performance. Research Qearterly for Exercise and Sports, 72(1), 63-67. https://doi.org/10.1080/02701367.2001.10608933

Kraemer, J. W., \& Vinger, L. J. (2007). Muscle Anatomy. Brown, E.L. (Ed.). Strength Training: National Strength and Conditioning Association. Champaign, IL: Human Kinetics.

Loturco, I., Artioli, G. G., Kobal, R., Gil, S., \& Franchini, E. (2014). Predicting Punching Acceleration From Selected Strength and Power Variables in Elite Karate Athletes: A Multiple Regression Analysis. Journal of Strength and Conditioning Research, 28(7), 1826-1832. https://doi.org/10.1519/JSC.0000000000000329

Loturco, I., D’Angelo, R. A., Fernandes, V., Gil, S., Kobal, R., \& Cal, A. C. C. (2015). Relationship Between Sprint Ability and Loaded / Unloaded Jump Tests in Elite Sprinters. Journal of Strength and Conditioning Research, 29(3), 758-764. https://doi.org/10.1519/JSC.0000000000000660

Newton, R. U., \& Kraemer, J. W. (1994). Developing Explosive Muscular Power: Implications for a Mixed Methods Training Strategy. Strength and Conditioning Association Journal, 16(5), 20-31. https://doi.org/10.1519/1073-6840(1994)016<0020:DEMPIF>2.3.CO;2

Ratamess, N. (2012). ACSM'S Foundations of Strength Training and Conditioning. Chine: Lippincott Williams \& Wilkins.

Sanchez-Medina, L., Gonzales-Badillo, J. J., Perez, C. E., \& Pallares, J. G. (2014). Velocity and Power - Load Relationship of the Bench Pull vs. Bench Press Exercises. International Journal of Sports Medicine, 35(3), 209-216.

Sanchez-Medina, L., Perez, C. E., \& Gonzales-Badillo, J. J. (2010). Importance of the Propulsive Phase in Strength Assessment. International Journal of Sports Medicine, 31(2), 123-129. https://doi.org/10.1055/s-0029-1242815

Sankarmani, B., Sheriff, S. I., Rajeev, K. R., \& Alagesan, J. (2012). Effectiveness of Plyometrics and Weight Training in Anaerobic Power and Muscle Strength in Female Athletes. International Journal of Pharmacautical Science and Health Care, 2(2), 172-180.

Stone, M. H., Sanborn, K., O'Bryant, H. S., Hartman, M., Stone, M. E., \& Proulx, C. (2003). Maximum Strength-Power Performance Relationships in College Throwers. Journal of Strength and Conditioning Research, 17(4), 739-745.

Yessin, M., \& Hatfield, F. (2007). Plyometric Training: Achieving Explosive Power in Sports. ( $3^{\text {rd }}$ Edition). Champaign, IL: Human Kinetics.

Young, W. B., Newton, R. U., Doyle, T. L., Chapman, D., Cormack, S., \& Stewart, G. (2005). Physiological and Anthropometric Characteristics of Starters and Non-Starters and Playing Positions in Elite Australian Rules Football: A Case Study. Journal of Science and Medicine in Sport, 8(3), 333-345. https://doi.org/10.1016/S1440-2440(05)80044-1

Zatsiorsky, V. M. (1998). Kinematics of Human Motion. Champaign, IL: Human Kinetics.

\section{Copyrights}

Copyright for this article is retained by the author(s), with first publication rights granted to the journal.

This is an open-access article distributed under the terms and conditions of the Creative Commons Attribution license which permits unrestricted use, distribution, and reproduction in any medium, provided the original work is properly cited. 